\title{
Neonatal corticosteroid permanently alters brain activity of epinephrine- synthesizing enzyme in stressed rats
}

BARBARA B. TURNER* RICHARD J. KATZ and BERNARD J. CARROLL

Mental Health Research Institute, University of Michigan, Ann Arbor, Mich. 48109 (U.S.A.)

(Accepted December 14th, 1978)

The enzyme responsible for the conversion of norepinephrine to epinephrine, phenylethanolamine N-methyltransferase (PNMT; E. C. 2.1.1.28), is present in the adrenal medulla ${ }^{1}$, other chromaffin tissues, sympathetic ganglia ${ }^{4}$, and the central nervous system ${ }^{15}$. Immunofluorescence and radioenzymatic assays have localized PNMT in discrete brain regions including the hypothalamus ${ }^{10,15}$. Cell bodies containing the enzyme are restricted to two cell groups in the rostral medulla of the brain stem, the ventral $\mathrm{C}_{1}$ region and the dorsal $\mathrm{C}_{2}$ region, areas which have established roles in cardiovascular regulation. The activity of non-specific N-methyltransferase is negligible in the brain stem ${ }^{\mathbf{1 4}}$. Epinephrine levels are reported to vary directly with PNMT activity in both adrenal and brain ${ }^{13,19}$.

Glucocorticoids are required for maximal activity of adrenal PNMT. In intact rats the physiological level of circulating corticosteroid appears to be virtually optimally effective, since supernormal levels of exogenous steroid do not result in increased activity of PNMT ${ }^{3,20}$.

In perinatal rats, treatment with the potent synthetic glucocorticoid, dexamethasone, produces a marked rise in PNMT activity in the superior cervical ganglion and other ganglia ${ }^{8,11}$. This increased is transitory, with enzyme activity falling rapidly after cessation of treatment. Neonatal dexamethasone administration has also been shown to increase PNMT activity in both hypothalamus and brain stem medulla ${ }^{13}$. In brain, the effect of glucocorticoid on PNMT activity has been examined only acutely, at the termination of steroid treatment. We wished to determine whether the neonatal enhancement of brain PNMT activity by dexamethasone might be a permanent effect. Such a finding would suggest that perinatal stress, with its concomitant rise in circulating glucocorticoids, as well as exposure to exogenous corticoids, can affect the level of synthesis of epinephrine in the adult animal.

Pregnant Sprague-Dawley rats from Charles River were received in midgestation. We pooled the pups on the day following parturition, and randomly

* To whom all correspondence should be sent at the following address: Departments of Psychology and Biology, Virginia Polytechnic Institute and State University, Blacksburg, Va. 24061, U.S.A. 


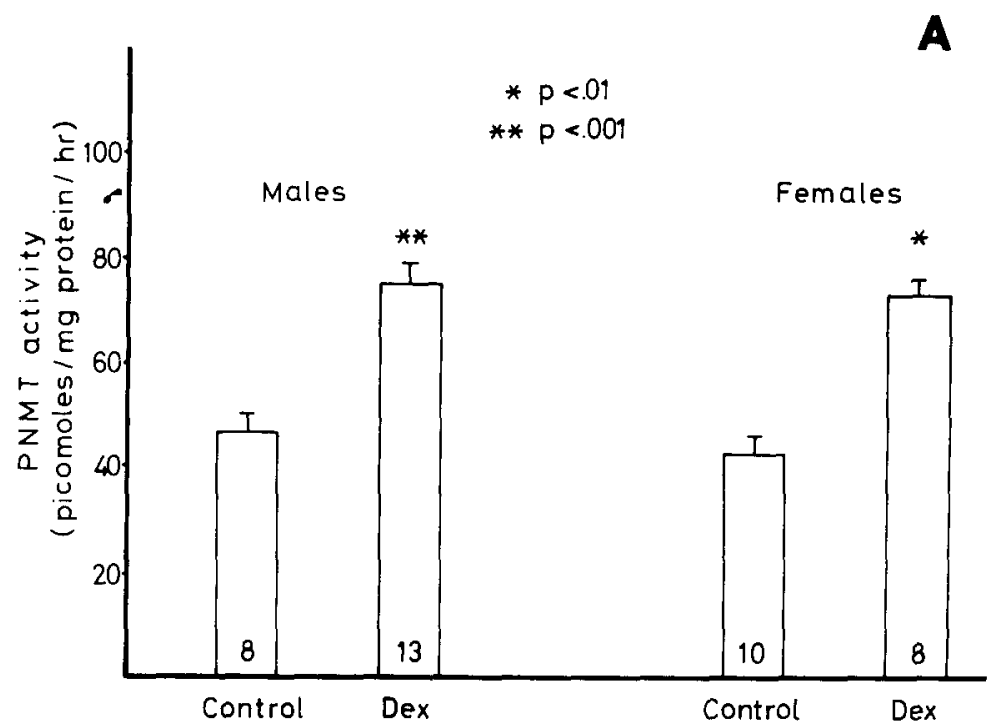

B

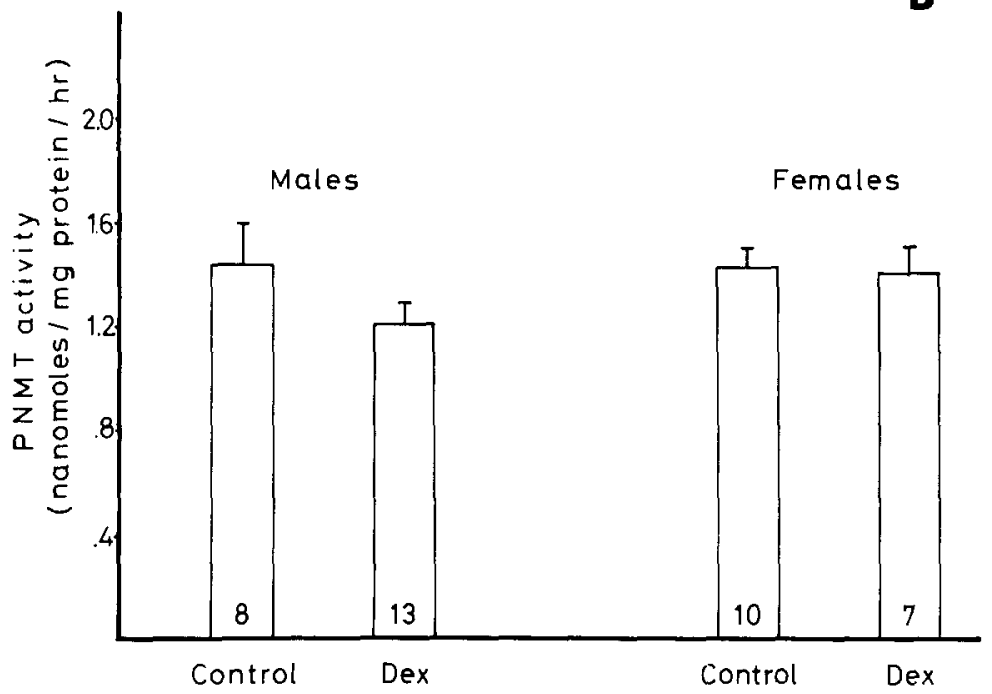

Fig. 1. PNMT activity following $30 \mathrm{~min}$ shaker stress in adult rats treated neonatally with dexamethasone. (A) brain stem; (B) adrenals. PNMT activity was assayed according to the method of Pendleton ${ }^{14}$ but with several modifications. [ $\left.{ }^{3} \mathrm{H}\right]$ methyl-S-adenosyl-1-methionine (New England Nuclear Corp., specific activity $10.2 \mathrm{Ci} / \mathrm{mmol}$ ) was used as the methyl donor together with unlabelled carrier to yield a final incubation molarity of $3 \times 10^{55} \mathrm{M}$. Triplicate determinations on $50 \mu 1$ aliquots were performed on all samples; homogenization volume was $100 \mathrm{mg} / \mathrm{ml}$ for brainstem and $50 \mathrm{mg} / \mathrm{ml}$ for adrenals. Proteins were measured by the method of Lowry ${ }^{12}$. Numbers at the base of the bars indicate the number of rats in each group. Vertical bars give the S.E.M. Probability values were obtained from Student's $t$ test, two tailed. 
composed litters of 10 . The pups assigned to the experimental group received dexamethasone indirectly, by way of steroid added to the drinking water of the dams $(2 \mathrm{mg} / \mathrm{l})$. Treatment, begun on postnatal day 2 or 3 , was continued for 4 days. This method of dexamethasone delivery to suckling rats is known to be effective9. At the time of weaning on day 25 , we noted no increase in mortality in the experimental group compared to the controls.

The weanling rats were group housed by sex and treatment and were sacrificed as adults at 4-5 months of age. In order to estimate maximal brain stem PNMT activity, we subjected the rats to acute stress, which as we have previously shown ${ }^{2}$, produces an elevation in enzyme activity. The stress procedure employed consists of placing each animal on a horizontal shaker for 30 min (shaker stress) immediately prior to sacrifice. Rats were decapitated between $0930-1130 \mathrm{~h}$, trunk blood collected for corticosterone determination, and the brains quickly removed and dissected on a chilled glass platform. We used a rectangular punch device $(5 \times 8 \mathrm{~mm})$ to standardize the brain stem dissection which included the $\mathrm{C}_{1}$ and $\mathrm{C}_{2}$ cell groups in the medulla oblongata. Adrenals and the dissected brainstems were frozen in liquid nitrogen and stored for subsequent PNMT assay. The combined results of the original experiment and a replication are presented.

As adults, the earlier dexamethasone treated rats had brain stem PNMT activities $61 \%(P<0.001)$ and $65 \%(P<0.01)$ higher in males and females respectively, than the controls (Fig. 1A). In contrast to this effect on brain PNMT activity, we

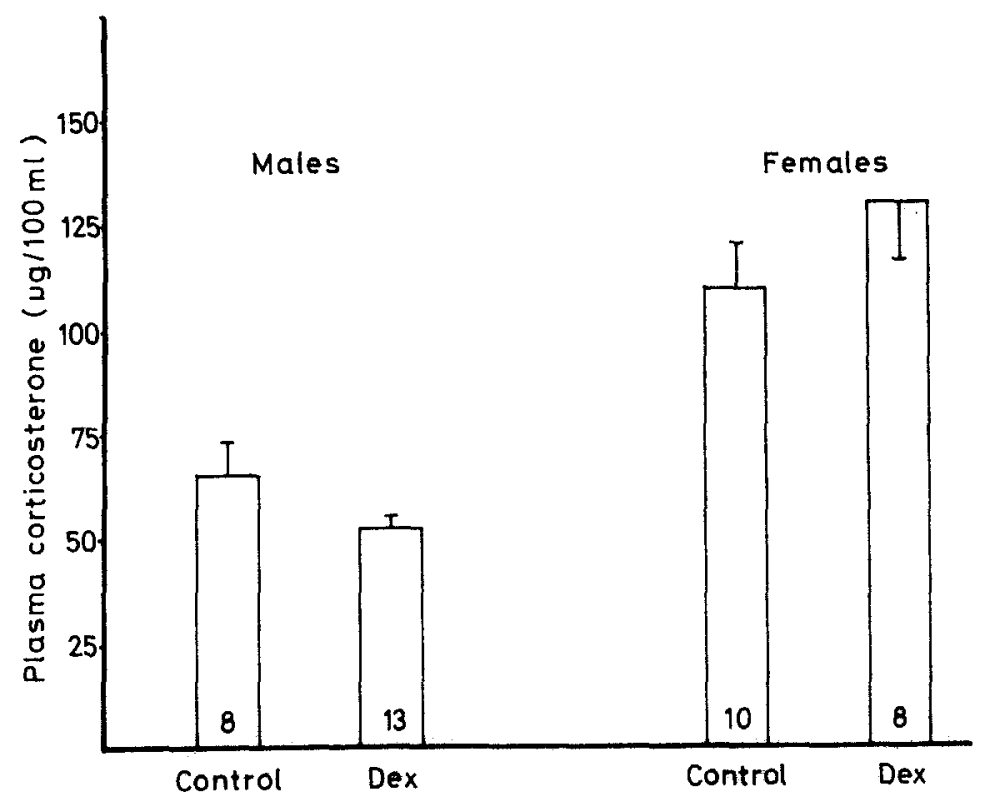

Fig. 2. Plasma of corticosterone after 30 minute shaker stress in adult rats which had been treated neonatally with dexamethasone. Corticosterone was assayed by a previously described competitive protein binding assay ${ }^{2}$ modified to increase sensitivity by using only $2 \%$ corticosteroid binding globulin. Each sample extract was assayed at two doses, each in duplicate. 
found that neonatal corticoid administration did not affect adrenal levels of PNMT activity in the animals as adults (Fig. 1B). The elevated activity in brain stem PNMT was not due to altered levels of plasma corticosterone produced by the dexamethasone exposure (Fig. 2).

Glucocorticoid treatment did not produce growth retardation as judged by body weights at the time of sacrifice. Neither pituitary nor adrenal organ weights differed significantly between the groups.

These results demonstrate that maximal (poststress) PNMT activity is higher in the early dexamethasone-treated animals. Whether this represents an exaggerated stress response or a permanent elevation in enzyme activity remains to be determined. It is possible that the observed increase in enzyme activity is directly related to stress since shaker stress does produce a significant rise in brain, but not adrenal PNMT ${ }^{18}$. However, we believe that it is more probable that this increased enzyme activity represents a chronic PNMT enhancement. Enhancement may be due to an increase in the number of enzyme molecules resulting either from cellular proliferation (such as neonatal dexamethasone produces in ganglia of the autonomic nervous system) or from actual enzyme induction (as apparently occurs in the adrenal). Elevated enzyme activity, however, could be due to a number of factors other than an increase in the number of PNMT molecules: decreased enzyme degradation; a decreased ratio of S-adenosylhomocysteine to Sadenosylmethionine ${ }^{6}$; altered substrate or product concentration ${ }^{7}$; or an ionic strength change in the immediate environment of the enzyme ${ }^{5}$.

Elevated brain stem PNMT activity is known to have physiological significance. Increased activity has been implicated in the development of genetic hypertension ${ }^{16}$. Experimentally hypertensive rats, which also have increased enzyme activity, show a reduction in blood pressure following the administration of a PNMT inhibitor. The participation of the epinephrine neuronal system in the stress reaction is evidenced by decreased levels of brain epinephrine and increased turnover of this neurotransmitter following footshock ${ }^{17}$.

The present finding emphasizes the differences between the mechanisms regulating PNMT activity in the brain and in the adrenal, and suggests that the brain enzyme is more sensitive than the adrenal enzyme to changes in hormonal parameters during development. We interpret our data as suggesting that chronic early stress, through the action of glucocorticoids, may permanently augment the increased epinephrine synthesis associated with stress in the mature animal.

We thank E. Smith, K. Roth, T. Willens and G. Baldrighi for excellent technical assistance. Supported by postdoctoral fellowships to BBT and RJK from NIMH through training grant $\mathrm{MH} 07417$ to the Mental Health Research Institute and by NIMH grant MH 28294 to BJC.

1 Axelrod, J., Purification and properties of phenylethanolamine N-methyltransferase, $J$. biol. Chem., 237 (1962) 1657-1660.

2 Carroll, B. J., Limbic system-adrenal cortex regulation in depression and schizophrenia, Psychosom. Med., 38 (1976) 106-121. 
3 Ciaranello, R. D. and Black, I. B., Kinetics of the glucocorticoid-mediated induction of phenylethanolamine N-methyl transferase in the hypophysectomized rat, Biochem. Pharmacol., 20 (1971) 3529-3532.

4 Ciaranello, R. D., Jacobowitz, D. and Axelrod, J., Effect of dexamethasone on phenylethanolamine N-methyltransferase in chromaffin tissue of the neonatal rat, J. Neurochem., 20 (1973) 799-805.

5 Cubeddu X. L., and Vargas, A. M., Effects of sodium chloride on phenylethanolamine Nmethyltransferase activity, Molec. Pharmacol., 13 (1977) 172-180.

6 Deguchi, T. and Barchas, J., Inhibition of transmethylations of biogenic amines by S-adenosylhomocysteine, J. biol. Chem., 246 (1971) 3175-3181.

7 Fuller, R. W. and Hunt, J. M., Inhibition of phenethanolamine N-methyltransferase by its product, epinephrine, Life Sci., 6 (1967) 1107-1112.

8 Gianutsos, G. and Moore, K. E., Effects of pre- or postnatal dexamethasone, adrenocorticotrophic hormone and environmental stress on phenylethanolamine $\mathrm{N}$-methyltransferase activity and catecholamines in sympathetic ganglia of neonatal rats, J. Neurochem., 28 (1977) 935-940.

9 Grota, L. J., Effects of dexamethasone on the development of emotionality and adrenocortical reactivity, Proc. 78th Ann. Conv., Amer. Psych. Assoc., (1970) 203-204.

10 Hökfelt, T., Fuxe, K., Goldstein, M. and Johansson, O., Immunohistochemical evidence for the existence of adrenaline neurons in the rat brain, Brain Research, 66 (1974) 235-251

11 Liuzzi, A., Foppen, F. H., Saavedra, J. M., Jacobowitz, D. and Kopin, I. J., Effect of NGF and dexamethasone on phenylethanolamine-N-methyltransferase (PNMT) Activity in neonatal rat superior cervical ganglia, J. Neurochem., 28 (1977) 1215-1220.

12 Lowry, O. H., Rosebrough, N. J., Farr, A. L. and Randall, R. J., Protein measurement with the Folin phenol reagent, J. biol. Chem., 193 (1951) 265-275.

13 Moore, K. E. and Phillipson, O. T., Effects of dexamethasone on phenylethanolamine N-methyltransferase and adrenaline in the brains and superior cervical ganglia of adult and neonatal rats, J. Neurochem., 25 (1975) 289-294.

14 Pendleton, R. G., Khalsa, J., Gessner, G. and Sawyer, J., Studies on the characterization and inhibition of rat brain phenylethanolamine $\mathrm{N}$-methyltransferase, Naunyn-Schmiedeberg's Arch. exp. Path. Pharmak., 299 (1977) 219-224.

15 Saavedra, J. M., Palkovits, M., Brownstein, M. and Axelerod, J., Localization of phenylethanolamine N-methyltransferase in the rat brain nuclei, Nature (Lond.), 248 (1974) 695-696.

16 Saavedra, J. M., Grobecker, H. and Axelrod, J. Adrenaline-forming enzyme in brainstem: elevation in genetic and experimental hypertension, Science, 191 (1976) 483-484.

17 Sauter, A. M., Baba, Y., Stone, E. A. and Goldstein, M., Effect of stress and phenylethanolamine$\mathrm{N}$-methyltransferase inhibition on central norepinephrine and epinephrine levels, Brain Research, 144 (1978) 415-419.

18 Turner, B. B., Katz, R. J., Roth, K. A., and Carroll, B. J., Central elevation of phenylethanolamine N-methyltransferase activity following stress, Brain Research, 153 (1978) 419-422.

19 Wurtman, R. J. and Axelrod, J., Adrenaline synthesis: control by the pituitary gland and adrenal glucocorticoids, Science, 150 (1965) 1464-1465.

20 Wurtman, R. J. and Axelrod, J., Control of enzymatic synthesis of adrenaline in the adrenal medulla bv adrenal cortical steroids, J. biol. Chem., 241 (1966) 2301-2305. 